\title{
The effect of substitution of zinc with aluminium in the brucite-like layers on the physicochemical properties of zinc-aluminium-layered double hydroxide-pamoate nanocomposite.
}

\begin{abstract}
Layered organic-inorganic hybrid materials of Zn-Al-layered double hydroxide (LDH)pamoate nanocomposite (ZAPR) were prepared using various initial $\mathrm{Zn} / \mathrm{Al}$ molar ratios (Ri) from 8:1 to 2:1 which gave initial values of $\mathrm{A} 3+/(\mathrm{Zn} 2++\mathrm{Al} \mathrm{3+)}$ mole fractions, (x i) from 0.11 to 0.33 . The $\mathrm{Al} 3+$ mole fractions in the resulting nanocomposite material $(\mathrm{x} \mathrm{f})$ were greater than $\mathrm{x} i$ and the difference between $\mathrm{x} i$ and $\mathrm{x} f$ was found to be a constant value of 0.03 . The increase in the $\mathrm{x} f$ values will increase the $\mathrm{Al} 3+$ content in the interlayer spaces of layered double hydroxide and therefore increases the charge density of the inorganic brucitelike layers and give stronger electrostatic attraction between the excess positive charge of $\mathrm{Al}$ $3+$ and the negative charge of the interlayer pamoate anion and hence decreases the d value of the material. However, the BET surface area of the resulting materials will decreases when the $\mathrm{x} f$ is increased. This shows that the mole fraction of $\mathrm{Zn} 2+$ replaced by $\mathrm{Al} 3+$ in the inorganic brucite-like layer plays an important role in controlling the physicochemical properties of the resulting material, which is particularly useful in determining tailor-made property required in the designed material.
\end{abstract}

Keyword: Physicochemical properties; Zinc-aluminium-layered double hydroxide; Pamoate; Nanocomposite. 